\title{
Experiences with Light-Coagulation
}

$\mathrm{J}$.

\author{
ten Doesschate
}

\section{Utrecht}

Published in full in Ned. T. Geneesk. 105: 820-826 (1961).

Summary

The results of photocoagulation carried out on 103 eyes are discussed. The material comprised the following cases: central retinal hole (14), peripheral retinal hole (39), cases of retinal detachment previously treated surgically (14), chorioretinitis (4), retinal periphlebitis (8), angioma of the retina (1), tumour of the choroid (16), retinoblastoma (7).

In many cases the results were entirely satisfactory; in other cases success was incomplete or no results were obtained.

The new equipment which is now available will no doubt yield a higher percentage of sucessful operations. 